Article

\title{
A Study on the Value of Preserving a Parasitic Volcanic Sieve as a Tourism Good for Sustainable Management: Using the Contingent Valuation Method
}

\author{
Won Seok Lee \\ Department of Tourism and Recreation, Kyonggi University, Seoul 03752, Korea; lws798@kgu.ac.kr
}

Received: 9 March 2020; Accepted: 31 March 2020; Published: 2 April 2020

\begin{abstract}
The purpose of this study is to estimate the economic value of Geomun Oreum (GO), a parasitic volcanic sieve, for sustainable management by using the dichotomous choice contingent valuation method. To address the exaggeration tendency of willingness to pay (WTP), the contingent valuation method's (CVM's) traditional threshold, respondents' WTP answers were reconfirmed to screen only true responses for our analysis. In addition to estimating the economic value, the causal relationship between the tour guide's quality of explanation and the respondents' payment intention is examined in the study. The results reveal that the estimated preservation value of GO is $35,881 \mathrm{KRW}$ (33.28 USD), and the quality of the tour guide's narrative is statistically related to the respondents' payment intention.
\end{abstract}

Keywords: contingent valuation method; sustainable preservation value; exaggeration bias; commentators' quality

\section{Introduction}

As a tourism destination, Jeju Island, located in the southern Korean Peninsula, is one of the most extensive and famous vacation destinations in Korea. Jeju Island was originally formed by a massive volcanic eruption and possesses an abundance of natural resources [1]. In recognition of the aesthetic and ecological value of Jeju Island, numerous developments and plans have been executed or announced to address future increases in tourism demand based on both domestic demand and the growing number of inbound tourists from neighboring countries. Oreums (small volcanoes; the Jeju local name for the parasitic volcanic sieve) are one of the unique natural ecological and tourism resources of Jeju Island. Most of the oreums in Jeju that remain in the present day still closely resemble their original appearance after the volcanic eruption. Therefore, they are recognized as a rare natural resource.

Of the oreums, the Geomun Oreum (GO hereafter) has been in the spotlight due to its uniqueness. Its name means "black oreum", and it provides key clues to understanding the formation process of lava tubes and has an important geological value because of its well-preserved volcanic landforms [2]. Moreover, it has historical and cultural value because it includes a charcoal kiln site, an army logistics road, a mine site built by the Japanese during the Pacific War, and a monument to the uprising of April 3, 1948 [3]. Owing to these unique characteristics, the GO was designated as Natural Monument No. 444 and listed as a World Natural Heritage site. It is now a representative ecotourism resource on Jeju Island with 300,000 visitors annually, and it has been operated and maintained with the cooperation of local authorities and residents of Jeju Island since 2015.

Hiking the GO is a fairly popular tourist activity, but access is permitted only with advance reservations and when accompanied by a village resident acting as a tour commentator. The role of 
the commentator is to convey information to tourists about the GO, which is located in the Gotjawal Forest, where hardy trees, brush and, moss grow on Jeju Island's volcanic terrain. Much of this land is untouched by human development, which has enabled a unique ecosystem to evolve.

As the superiority and uniqueness of natural resources in this area have recently been highlighted, related development plans are being discussed. At the same time, some have voiced concern about the loss of valuable natural resources through such development. Specifically, there has been talk of business development in the Gotjawal Forest; however, claims are also being made about the need for preservation in recognition of the environmental value of the area. To justify either development or preservation, estimating quantified values and a value assessment will inevitably be necessary. If the value of preservation is greater than the value of development, then the argument for preservation will be strongly supported.

The contingent valuation method (CVM), a systematic method that can estimate the value of nonmarket goods, has frequently been applied in various academic fields [4-6]. The main logic of the CVM is to determine how much individuals are willing to pay by setting up a hypothetical market situation and asking them about their willingness to pay (WTP) for nonmarket goods in that situation. The estimate of economic value can help determine a justification for sustainable preservation if the benefits from preservation are higher than the benefits from development [5].

Despite the advantages of the CVM method, it is criticized for having a hypothetical bias that can ultimately result in overestimating the value of nonmarket goods [7]. To minimize the limitations of the CVM, previous CVM studies have reaffirmed respondents' answers by adding a series of confirmation questions called "real-world" questions [4,8]. By filtering out unreliable responses through real-world questions, a more precise value can be estimated $[9,10]$. In addition to the economic value of the GO, we will investigate the relationship between the quality of the tour guides' narratives and the respondents' payment intentions because previous spending preference literature has shown that psychological and emotional variables are likely to significantly influence individuals' behavioral intentions [11]. However, few studies have statistically demonstrated the relationship between the psychological state that emerges from the narrative service and payment intention.

Given the need for quantitative data and accurate estimates to preserve the GO, the two key objectives of the study are to (1) estimate the value of the preservation of the GO by employing the CVM and (2) reduce the exaggeration bias of the CVM results. In addition, the final purpose of the study is to (3) demonstrate the statistical relationship between the quality of the tour guide's narrative and its role in respondents' WTP.

\section{Literature Review}

\subsection{Contingent Valuation Method}

In the previous traditional tourism development paradigm, central or local governments have been highly active in the development of tourism resources because they aim to capture the enormous economic benefits that these can deliver [12]. More recently, however, there has been debate as to whether the preservation of tourism resources could bring larger benefits to communities in the long run given the ecological value of tourism resources. Therefore, CVM research is actively used in the areas of "development" and "preservation", which are always of interest within the area of tourism development [5,13-15],

The CVM is recognized as a systematic method for estimating the value of nonmarket goods that cannot be estimated by market mechanisms, wherein supply and demand meet to establish the price $[9,16,17]$. The main process of the CVM is to set up a hypothetical market situation (payable condition) and to require a response providing the value of nonmarket goods, which are public goods that individuals cannot own, in the form of WTP. The well-known advantage of the CVM method is the flexibility of its application because the hypothetical scenario used in CVM makes it easy to apply market conditions $[4,6,18]$. Most tourism resources are nonmarket goods. Therefore, research is 
being actively conducted in tourism studies to estimate the value of tourism resources through the CVM. For example, Choi, Lee, Lee, and Dattilo (2015) attempted to estimate the economic value of mud in use at a mud festival as a tourism resource through the CVM method [19,20]. Additionally, Mjelde, Kim, Kim, and Lee estimated the economic value of the Korean Demilitarized Zone (DMZ) as a nonmarket and tourism good [21]. Furthermore, some CVM studies treat leisure services as a study subject and justify preservation by employing the CVM [22,23].

To inquire about respondents' WTP, a type of "open" or "closed" question has been used in CVM survey questionnaires; however, the preferred method is the dichotomous (DC) type of question [4,14,21,24-27]. For DC questions, respondents answer only "yes" or "no" in response to a given price for the preservation or use of the research object; this approach, which resembles an actual decision-making mechanism, may make it easier to respond $[9,10]$.

Despite the CVM's ability to estimate the value of nonmarket goods, the estimated value is more likely to be exaggerated as a result of the application of a hypothetical situation [28-31]. In general, hypothetical scenarios are presented in CVM studies to create a payment environment for nonmarket goods, but they can cause respondents to distort the current state of their resources or to make response errors. To overcome the limitations of the traditional CVM, respondents' WTP answers are reaffirmed with a series of additional questions called "real-world" questions [14,32]. In other words, respondents' "true" answers are identified by screening through additional questions called "real-world questions", and only when the respondents' sincerity has been confirmed are the data used in the analysis. Some CVM studies have concluded that applying these real-world questions can reduce exaggeration of the estimates [20,30]. Therefore, given the arguments in the previous literature that exaggerated estimations have been mitigated by reconfirming the respondents' answers, which can ultimately lead to a more conservative estimate of WTP, we employ the same procedure to increase the reliability of respondents' WTP answers for the GO.

\subsection{The Effect of Interpreter Quality}

Tour guide services are considered an important attribute in the success of a tour [33-38]. Therefore, numerous tourism scholars have analyzed the effects of tour guides' role or the quality of the guide's narrative on tourists' psychological or emotional factors [39], [34,40,41]. For example, the authors of [42] argued that tourists' level of satisfaction is related to the quality of the service provided by the tour guide and that the capabilities of the tour guide are related to the tourists' recommendation of the product. It has also been shown that the guide's ability is related to the satisfaction, evaluation, and place attachment of tourists [43-45].

Despite the abundant evidence from prior studies that the quality of the tour narrative has an influence on tourism behaviors, few studies have shown that the quality of the narrative affects respondents' payment intentions. Therefore, we will additionally identify the causal relationship between the quality of the narrative and respondents' payment intentions in the GO context.

\section{Method}

\subsection{Model Specifications}

The first step for the CVM analysis is to identify the price categories to be provided to respondents. There are 9 predetermined amounts in the study $(100,1000,3000,5000,10,000,30,000,50,000,70,000$, and 100,000 KRW) chosen based on evidence from the literature, the field, and academic experts' opinions. The decision was made by asking each of the three experts in industry and academia about the scope of the preservation fund. Then, one randomly selected price from that price category was presented to respondents, and they were asked to respond "yes" or "no" in the DC CVM [46,47]. According to utility maximization theory, the theoretical basis of the CVM, respondents should choose 
the item that has greater utility. Similarly, respondents choosing between "pay" (yes) and "not pay" (no) would choose the option with greater utility, as shown in Equation (1):

$$
\begin{gathered}
v(1, Y-B ; s)+\in 1 \geq v(0, Y ; s)+\in 0 \\
U=v(j ; Y ; s)+\epsilon j j=0,1
\end{gathered}
$$

where $v$ is the indirect utility function, 1 represents paying a donation and 0 represents not paying, $B$ is a randomly offered amount, $Y$ is income, and $s$ denotes other socioeconomic characteristics affecting individual choice; 0 and 1 are the identically, independently distributed random variables with zero means. The utility difference can be described as shown in Equation (2):

$$
\Delta v=v(1, Y-B ; s)-v(0, Y ; s)+\left(\varepsilon_{1}-\varepsilon_{0}\right)=v(1, Y-B ; s)-v(0, Y ; s)
$$

\subsection{Logit Model and Payment Method}

The probability $\left(P_{i}\right)$ that the individual will accept the given price can be expressed as the following logit model [46]:

$$
P_{i}=F_{\eta}=(\Delta v)=\frac{1}{1+\exp (-\Delta v)}=\frac{1}{1+\exp \{-(\alpha+\beta A+\gamma C+\lambda S)\}}
$$

where $F_{\eta}$ is the cumulative distribution function of a standard logistic variate; some socioeconomic variables are included in this research model. $\beta$ and $\gamma$ are coefficients to be estimated. The logit model in Equation (4) is then estimated using the maximum likelihood estimation method, the most common technique for estimating a logit model [48].

$$
W T P=\int_{0}^{\infty} F \eta(\Delta \mathrm{v}) \mathrm{dA}=\int_{0}^{\infty} \frac{1}{1+e^{-\left(\alpha^{*}+\beta^{*} b i d\right)}} d A
$$

where $\alpha^{*}$ is the sum of the constant and the coefficient of the socioeconomic variables multiplied by the mean of the variables. There are three methods to compute the value of WTP: The first method, WTP mean, is to calculate the expected value of WTP by numerical integration ranging from 0 to $\infty$; the second method, WTP overall mean, is to calculate the expected value of WTP by numerical integration ranging from $-\infty$ to $+\infty$; and the third method, WTP truncated mean, is to calculate the expected value of WTP by numerical integration ranging from 0 to the maximum bid (B) [12]. The WTP truncated mean method is selected to compute the conservation value of the GO in the study.

\subsection{Research Design}

In the CVM, a hypothetical scenario designed to capture what might happen in the real world should be established to create a situation in which respondents can express their WTP [49]. Moreover, the scenario should be realistic because the content of the proposed scenario could affect the respondents' WTP answers. Thus, the following hypothetical scenarios were established and presented to the respondents before they answered:

"Geomun Oreum was listed as a World Natural Heritage site in 2007 and was selected as one of the top 10 Korean ecotourism models in 2010. Geomun Oreum, which is of great importance in the ecosystem and as a tourism resource, is likely to be damaged as an ecological tourist destination due to the increasing interest in and increasing threat of development of the Gotjawal Forest. For the preservation and operations of Geomun Oreum, additional funds will be necessary."

After respondents read the scenario, they were asked the WTP questions. A randomly selected amount (predetermined amounts selected through the literature review and experts' opinions) was presented, and respondents were asked to choose "yes" or "no" for the first question. If the respondents 
answered "yes" to the first question, they would encounter two additional questions that would confirm the sincerity of their response regarding payment. The following are the questions used in the study:

Q1. Geomun Oreum is popular as a tourism resource, and numerous tourists are visiting it. Recently, interest in GO has been growing, leading to a sharp increase in visitors. In the future, the increase in tourists will cause damage to GO's natural resources. If a donation was collected to preserve the GO, would you be willing to contribute [X] KRW (Korean won) to this fund (only once a year)?

1. Yes 2. No

Q2. If you answered "yes" above, do you agree to receive an electronic bill to donate [x] to KRW?

1. Yes 2. No

Q3. If you answered "yes" in the second question, would you be willing to provide your name and address?

$\begin{array}{ll}\text { 1. Yes } & \text { 2. No }\end{array}$

To measure the quality of the tour commentators' service, we modified and supplemented the study of Look [50]. We then used a Likert measurement scale (1: Not at all to 5: Very good) consisting of 11 items related to ecotourism guide quality.

\subsection{Data Collection}

Data were collected from November 18 to November 20, 2017. An on-site survey was conducted for returning visitors after they had experienced the GO, and two research assistants trained in the content of the survey approached every fifth visitor over 18 years old and asked if they would complete a survey. A self-administered method was adopted for the individuals who agreed to participate in the survey. A total of 274 survey questionnaires were initially distributed. However, 24 returned surveys were deleted due to missing data, and 250 surveys were ultimately used for the analysis.

\section{Results}

\subsection{Demographics of Respondents}

As shown in Table 1, among the respondents, there were $122(48.8 \%)$ males and $128(51.2 \%)$ females. By age group, $77(30.8 \%)$ were in their $40 \mathrm{~s}, 65(26.0 \%)$ were in their $50 \mathrm{~s}, 43$ were in their $30 \mathrm{~s}$ $(17.2 \%), 40$ were in their $20 \mathrm{~s}(16.0 \%)$, and the remainder were in their $60 \mathrm{~s}(10.0 \%)$. 
Table 1. Demographic characteristics of respondents $(\mathrm{N}=250)$.

\begin{tabular}{ccc}
\hline & & \# of respondent (\%) \\
\hline \multirow{2}{*}{ Gender } & Male & $122(48.8)$ \\
& Female & $128(51.2)$ \\
Age & $20 \mathrm{~s}$ & $39(15.6)$ \\
& $30 \mathrm{~s}$ & $43(17.2)$ \\
& $40 \mathrm{~s}$ & $77(30.8)$ \\
Household monthly income & $50 \mathrm{~s}$ & $65(26.0)$ \\
(KRW) & Over 60 & $25(10.0)$ \\
& Less than 100 & $22(8.8)$ \\
& $100 \sim$ Less than 200 & $33(13.2)$ \\
& $200 \sim$ Less than 300 & $60(24.0)$ \\
Academic background & $300 \sim$ Less than 400 & $65(26.0)$ \\
& $400 \sim$ Less than 500 & $21(8.4)$ \\
& $500 \sim$ Less than 600 & $26(10.4)$ \\
& $600 \sim$ Less than 700 & $8(3.2)$ \\
& More than 700 & $13(5.2)$ \\
& Less than middle school & $11(4.4)$ \\
& Less than high school & $43(17.2)$ \\
& Gttending university/college & $30(12.0)$ \\
& Graduated university/college & $143(57.2)$ \\
& Graduate school & $21(8.4)$ \\
\hline
\end{tabular}

Note: Unit of household income: Million won.

Table 2 shows the items and the statistical results. According to Table 2, the mean of all of the items was above four points, and the standard deviations were less than one, confirming that the variance in the response was not significant.

Table 2. Measurement of ecotourism guide's quality.

\begin{tabular}{ccc}
\hline Variable & Mean & Standard Deviation \\
\hline Quality of explanation (Cronbach's alpha $=0.948)$ & \\
Communication with the interpreter was meaningful. & 4.50 & 0.788 \\
Interpreter made the commentary easy to understand. & 4.44 & 0.854 \\
The interpreter's communication was satisfactory. & 4.40 & 0.821 \\
The explanation time was opportune. & 4.32 & 0.854 \\
The distance from the interpreter was close. & 4.31 & 0.888 \\
The & 0.881 \\
resources. & 0.758 \\
After hearing about Geomun Oreum, an understanding was reached. & 4.38 & 0.931 \\
After listening to the explanations, I gained knowledge of ecological & 4.04 & \\
Ofter listening to the explanations, I gained knowledge of Geomun & 4.24 & 0.849 \\
Oreum. & 0.773 \\
The interpreter has the expertise to provide an interpretation service. & 4.38 & 0.798 \\
The interpreter's explanation of Geomun Oreum was satisfactory. & 4.32 & \\
\hline
\end{tabular}

"Yes" rate regarding the preservation value of Geomun Oreum.

Table 3 shows the response rates for the WTP questions. As shown in Table 3 and Figure 1, in general, the "yes" response rates decreased as the given amount increased, which implies that respondents were less likely to pay higher amounts as a preservation fund. Additionally, the percentage of "yes" responses decreased when "yes" answers were double-checked with real-world questions. That is, even if the respondents answered "yes" to the first question, they then answered "no" to a more serious question (agreeing to provide an email address and accepting an electronic bill). This pattern could be interpreted as an insincere response in the first "yes", so under this pattern, the first "yes" was ultimately considered a "no" and was reflected as such in the data analysis. 
Table 3. Comparison of willingness to pay (WTP) probabilities between hypothetical and real settings.

\begin{tabular}{ccccccccccc}
\hline $\begin{array}{c}\text { Proposed } \\
\begin{array}{c}\text { Amount } \\
\text { (KRW) }\end{array}\end{array}$ & Total & \multicolumn{3}{c}{ WTP 1 } & \multicolumn{3}{c}{$\begin{array}{c}\text { WTP 2 } \\
\text { (Bank Account) }\end{array}$} & \multicolumn{3}{c}{$\begin{array}{c}\text { WTP 3 } \\
\text { (Address and email) }\end{array}$} \\
\cline { 2 - 11 }$y$ & & Yes & No & Yes \% & Yes & No & Yes \% & Yes & No & Yes \% \\
\hline 100 & 28 & 24 & 4 & 85.7 & 23 & 5 & 82.1 & 20 & 8 & 71.4 \\
1000 & 26 & 23 & 3 & 88.5 & 20 & 6 & 76.9 & 19 & 7 & 73.1 \\
3000 & 27 & 23 & 4 & 85.2 & 22 & 5 & 81.5 & 19 & 8 & 70.4 \\
5000 & 28 & 23 & 5 & 82.1 & 22 & 6 & 78.6 & 16 & 12 & 57.1 \\
10,000 & 32 & 18 & 14 & 56.3 & 17 & 15 & 53.1 & 13 & 19 & 40.6 \\
30,000 & 28 & 12 & 16 & 42.9 & 9 & 19 & 32.1 & 5 & 23 & 17.9 \\
50,000 & 28 & 6 & 22 & 21.4 & 4 & 24 & 14.3 & 2 & 26 & 7.1 \\
70,000 & 25 & 3 & 22 & 12.0 & 2 & 23 & 8.0 & 2 & 23 & 8.0 \\
100,000 & 28 & 0 & 28 & 0 & 0 & 28 & 0 & 0 & 28 & 0 \\
Total & 250 & 132 & 118 & 52.68 & 119 & 131 & 47.40 & 96 & 154 & 38.40 \\
\hline
\end{tabular}

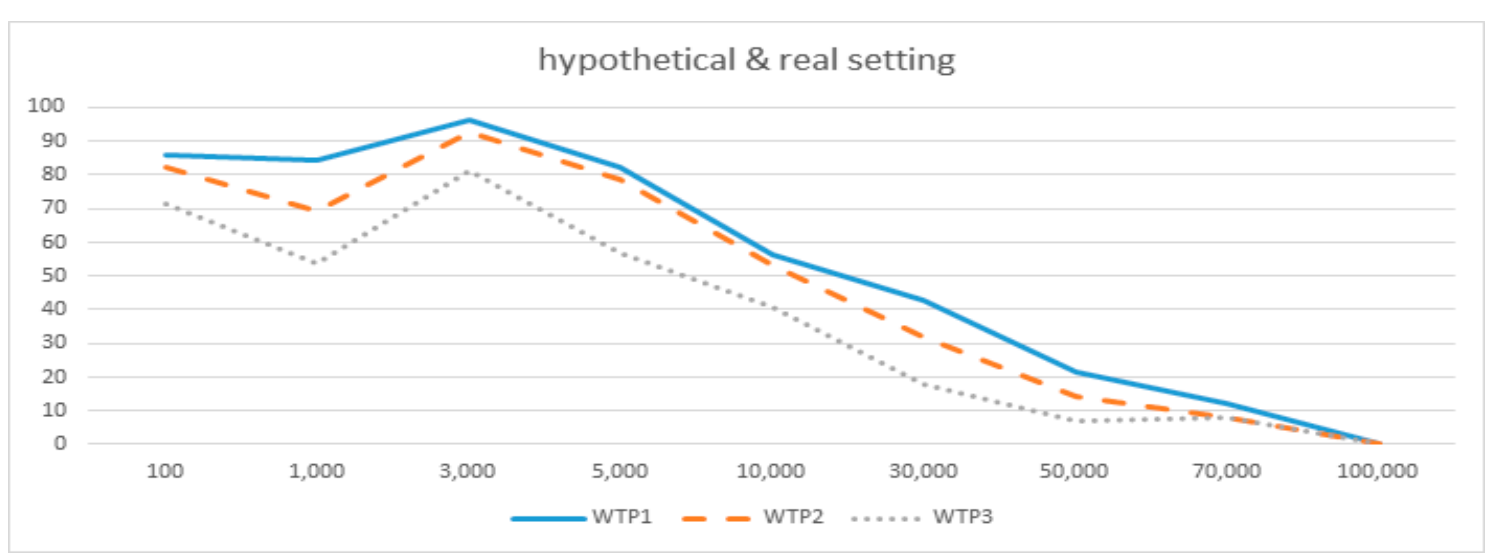

Figure 1. Comparison of WTP probabilities between hypothetical and real settings.

\subsection{Logit Model Estimation Results}

Based on the type of dependent variable (binary: "Yes" or "no"), a logistic regression was appropriate for analyzing the data [51]. As independent variables, a "bid price" (a given amount), gender, age, monthly income, and commentator quality were statistically tested. In addition, the regression coefficients were estimated using maximum likelihood estimation. Table 4 shows the results of the logistic models. WTP1 is an indication of the results of the analysis with the first response data. Similarly, WTP2 is the result of the analysis based on the data from WTP questions 1 and 2. Finally, WTP3 is a statistical result based on the answers to all three questions. The results show that the significant variables that affect individuals' WTP are the bid price and the quality of the tour guides, while gender, age, and monthly income do not affect WTP.

The direction of the coefficient of the bid price is negative (-), implying that the lower the proposed amount is, the higher the WTP for the preservation fund for the GO. In addition, the quality of the tour narrative and WTP are positively related, indicating that the higher the quality of the tour, the more respondents are willing to pay for the preservation of the GO. 
Table 4. WTP logit model estimation results.

\begin{tabular}{|c|c|c|c|c|c|c|c|c|c|c|c|c|}
\hline \multirow{2}{*}{ Variable } & \multicolumn{4}{|c|}{ WTP1 } & \multicolumn{4}{|c|}{ WTP2 } & \multicolumn{4}{|c|}{ WTP3 } \\
\hline & Estimation & Standard Error & Wald & Sig. & Estimation & Standard Error & Wald & Sig. & Estimation & Standard Error & Wald & Sig. \\
\hline Constant & -2.642 & 1.607 & 2.704 & 0.100 & -0.777 & 1.506 & 0.441 & 0.507 & -2.048 & 1.445 & 2.008 & 0.157 \\
\hline Amount & -0.000077 & 0.000010 & 60.613 & $0.000 * *$ & -0.000074 & 0.000010 & 55.655 & $0.000 * *$ & -0.000067 & 0.000011 & 40.249 & $0.000 * *$ \\
\hline Gender & -1.429 & 0.430 & 11.025 & $0.001 *$ & -1.238 & 0.393 & 9.938 & $0.002 *$ & -0.353 & 0.342 & 1.066 & 0.302 \\
\hline Age & -0.013 & 0.016 & 0.709 & 0.400 & -0.026 & 0.015 & 2.842 & 0.092 & -0.027 & 0.014 & 3.933 & 0.047 \\
\hline $\begin{array}{l}\text { Household } \\
\text { monthly income }\end{array}$ & -0.059 & 0.118 & 0.252 & 0.616 & -0.076 & 0.109 & 0.478 & 0.489 & -0.061 & 0.098 & 0.392 & 0.531 \\
\hline $\begin{array}{l}\text { Quality of } \\
\text { explanation }\end{array}$ & 1.799 & 0.358 & 25.251 & $0.000 * *$ & -0.999 & 1.506 & 0.441 & 0.507 & 1.096 & 0.307 & 12.694 & $0.000^{* *}$ \\
\hline
\end{tabular}

Note $1:{ }^{*}$ indicates significance at the 0.05 level. Note $2:{ }^{* *}$ indicates significance at the 0.01 level. 


\subsection{Preservation Value of the GO Estimated by the WTP Truncated Method}

As shown in Table 5, the estimated preservation value of the GO calculated by the truncated method is $64,169 \mathrm{KRW}$ for WTP1, 61,717 KRW for WTP2 (estimated based on responses after the first and second reaffirming questions, respectively), and 35,881 KRW for WTP3 (estimated based on responses after all three reaffirming questions). By taking into account the decrease in the amount of estimated WTP, we believe that the exaggeration bias issues have been mitigated. That is, real-world questions could play an important role in reducing the bias associated with a hypothetical scenario. This reduction has been externally validated by previous studies [21,52]. Considering the refining effect of real-world questions, we believe that $35,881 \mathrm{KRW}$ is close to the amount that individuals are likely to be willing to pay for the GO in a real-life setting.

Table 5. WTP truncated.

\begin{tabular}{llcc}
\hline & WTP 1 & WTP 2 & WTP 3 \\
\hline WTP truncated (KRW) & 64,169 KRW & 61,717 KRW & $35,881 \mathrm{KRW}$ \\
\hline & Note: 1 dollar = 1078 KRW.
\end{tabular}

\section{Conclusions}

The GO is located within the "Gotjawal Forest", a forest of hardy trees, brush, and moss that grow in Jeju Island's volcanic terrain; thus, there is a strong claim for ecological and sustainable preservation. As a method for estimating the value of nonmarket goods such as the GO, the CVM has frequently been used in tourism contexts. Considering the possibility of the destruction of natural resources by an increasing number of visitors and potential development plans, it is necessary to quantify the economic value of the GO. This research is academically significant in that quantifying the value of the GO could provide a reference to support or inhibit the development of resources. As a result, we estimate that individuals' WTP is $35,881 \mathrm{KRW}$, and the preservation value is approximately 10.1 billion KRW (10,553,235 USD), given an annual number of visitors to the GO reaching 300,000 (to derive the estimated amount, WTP is multiplied by the number of visitors). The estimated value of the GO can be used as the basis for policy decisions of sustainable preservation. This result could also be used as a reference to create additional financial resources, such as new admission fees or to adjust existing fees. In other words, the results of the study can be used as a yardstick for creating new resources for efficient conservation of valuable natural resources. Based on the results of WTP per person, an appropriate line can be provided for determining financial resources, such as admission fees or parking fees. An appropriate new offer of admission fees would lower the resistance to additional collection by tourists.

Another important phase of this study is the investigation of the causal relationship between the quality of the guide's narrative and intention to pay for the GO. Given the evidence that individuals' behaviors vary depending on psychological conditions, we assumed that narrative quality would be connected with visitors' payment intentions and statistically examined the relationship, which could contribute to expanding the scope of the literature on payment intention. Because the quality of the commentary could increase the WTP of tourists, practical consideration should be given to improving the quality of the tour guides' narratives. In practical terms, the GO is the only hiking site in Jeju where visitors are accompanied by a guide. Because visitors have expressed their intention to pay more for the preservation of the GO depending on the quality of the guide, the guides should be trained and their content systematically developed. For example, it is necessary to regularly evaluate commentators' knowledge of the GO to determine if there are deficiencies or mistakes in that knowledge, and then improvement and rectification should be made through education. Moreover, a commentator is generally a local resident and has never been professionally trained in customer handling. Therefore, inviting customer handling training specialists to train commentators on their response services would be a good idea on the grounds that service manners can also affect customer satisfaction. 
Additionally, we attempted to reduce the exaggeration bias, which is a traditional limitation of the CVM, by reaffirming the respondents' answers. We could argue that the estimated value will not be exaggerated by using only data for which the sincerity of the response has been confirmed. This study addresses the traditional weakness that exaggeration can lead to lower reliability in the CVM results, which is another academic contribution of this study.

This study has the following limitations, which are intended to be addressed by future research. First, the sample in this study is concentrated in a specific population group, with $56.8 \%$ of individuals being in their 40s-50s, which could cause potential problems with generalization. It should also be considered that the environmental conditions of respondents, such as the geographical location of their residence or their nationality, would affect WTP responses. Second, the suggestion that narratives can affect payment intention requires additional verification before it is generalized. In other words, further verification will be needed to generalize the results of the study.

Funding: This work was supported by Kyonggi University Research Grant 2017.

Conflicts of Interest: The author declares no conflict of interest.

\section{References}

1. Koh, S.Y. The Inscription of Jeju World Natural Heritage and Ecotourism in Jeju. J. Korean Assoc. Reg. Geogr. 2009, 15, 215-225.

2. Ko, M.Y.; Ko, G.S.; Yang, P.S. Market segmentation of the World Natural Heritage Site visitors using tourism motivation: A case study of Geomun oreum. J. Korea Tour. Res. 2011, 35, 11-30.

3. Ki, J.S.; Jeon, Y.; Ryu, C.K.; Kim, S.S. A signification and meaning of Geomun oreum as a representative geo site of global Geo parks. J. Geol. Soc. Korea 2016, 52, 763-774. [CrossRef]

4. Egan, K.J.; Corrigan, J.R.; Dwyer, D.F. Three reasons to use annual payments in contingent valuation surveys: Convergent validity, discount rates, and mental accounting. J. Environ. Econ. Manag. 2015, 72, 123-136. [CrossRef]

5. Marella, G.; Raga, R. Use of the Contingent Valuation Method in the assessment of a landfill mining project. Waste Manag. 2014, 34, 1199-1205. [CrossRef]

6. Mitchell, R.C.; Carson, R.T. Current Issues in the Design, Administration, and Analysis of Contingent Valuation Surveys; University of California San Diego: San Diego, CA, USA, 1993.

7. Mitchell, R.C.; Carson, R.T.; Carson, R.T. Using Surveys to Value Public Goods: The Contingent Valuation Method; Resources for the Future: Washington, DC, USA, 1989.

8. Parsons, G.; Myers, K. Fat tails and truncated bids in contingent valuation: An application to an endangered shorebird species. Ecol. Econ. 2016, 129, 210-219. [CrossRef]

9. Freeman, A. The measurement of environmental and resource value: Theory and methods-A myrisk Freeman III resources for the future. Resour. Policy 1994, 20, 281-282.

10. Hanemann, M.; Loomis, J.; Kanninen, B. Statistical efficiency of double-bounded dichotomous choice contingent valuation. Am. J. Agric. Econ. 1991, 73, 1255-1263. [CrossRef]

11. Park, J.H.; MacLachlan, D.L. Estimating willingness to pay with exaggeration bias-corrected contingent valuation method. Mark. Sci. 2008, 27, 691-698. [CrossRef]

12. Lee, C.K. Valuation of nature-based tourism resources using dichotomous choice contingent valuation method. Tour. Manag. 1997, 18, 587-591. [CrossRef]

13. Chong, K.Y.; Balasingam, A.S. Tourism sustainability: Economic benefits and strategies for preservation and conservation of heritage sitesin Southeast Asia. Tour. Rev. 2019, 74, 281-292. [CrossRef]

14. Lee, C.K.; Mjelde, J.W. Valuation of ecotourism resources using a contingent valuation method: The case of the Korean DMZ. Ecological Economics 2007, 63, 511-520. [CrossRef]

15. Lee, H.J. The Effect of Anxiety, Prior Knowledge, and Self-development Motivation on Tourists' Preference for Tour-guiding Service. Int. J. Tour. Hosp. Res. 2012, 26, 205-223.

16. Heo, J.W. Estimation of Economic Value for Cultural Tourism Festivals and Its Determinants: The Case of Jeongson World Arirang Festival. J. Korea Tour. Res. 2007, 22, 343-363.

17. Lee, C.K.; Han, S.Y. Estimating the use and preservation values of national parks' tourism resources using a contingent valuation method. Tour. Manag. 2002, 23, 531-540. [CrossRef] 
18. Lee, W.S.; Graefe, A.R.; Hwang, D. Willingness to pay for an ecological park experience. Asia Pac. J. Tour. Res. 2013, 18, 288-302. [CrossRef]

19. Carson, R.; Mitchell, R. The issue of scope in contingent valuation studies. Am. J. Agric. Econ. 1993, 75, 1263-1267. [CrossRef]

20. Choi, Y.; Lee, W.S.; Lee, C.K.; Dattilo, J. Valuation of mudflats in nature-based tourism: Inclusion of perceived value of festival experiences. Tour. Econ. 2015, 21, 833-851. [CrossRef]

21. Mjelde, J.W.; Kim, H.; Kim, T.K.; Lee, C.K. Estimating Willingness to Pay for the Development of a Peace Park Using CVM: The Case of the Korean Demilitarized Zone. Geopolitics 2017, 22, 151-175. [CrossRef]

22. Lee, W.S.; Lee, C.K.; Yoon, Y.; Kim, J. Research note: Exaggeration bias-corrected contingent valuation method: The case of Olle Trail. Tour. Econ. 2015, 21, 1323-1330. [CrossRef]

23. Lee, W.S.; Kim, J.; Graefe, A.R.; Chi, S.H. Valuation of an eco-friendly hiking trail using the contingent valuation method: An application of psychological ownership theory. Scand. J. Hosp. Tour. 2013, 13, 55-69. [CrossRef]

24. Boyle, K.J.; Bishop, R.C. Welfare measurements using contingent valuation: A comparison of techniques. Am. J. Agric. Econ. 1988, 70, 20-28. [CrossRef]

25. Han, S.Y.; Lee, C.K. Estimating the value of preserving the Manchurian black bear using the contingent valuation method. Scand. J. For. Res. 2008, 23, 458-465. [CrossRef]

26. Hanemann, W.M. Welfare evaluations in contingent valuation experiments with discrete response data: Reply. Am. J. Agric. Econ. 1989, 71, 1057-1061. [CrossRef]

27. Loomis, J.B. Contingent valuation using dichotomous choice models. J. Leis. Res. 1988, 20, 46-56. [CrossRef]

28. Arrow, K.; Solow, R.; Portney, P.R.; Leamer, E.E.; Radner, R.; Schuman, H. Report of the NOAA panel on contingent valuation. Fed. Regist. 1993, 58, 4601-4614.

29. Hanley, N. Using contingent valuation to value environmental improvements. Appl. Econ. 1988, 20, 541-549. [CrossRef]

30. Johannesson, M.; Liljas, B.; Johansson, P.O. An experimental comparison of dichotomous choice contingent valuation questions and real purchase decisions. Appl. Econ. 1998, 30, 643-647. [CrossRef]

31. Langford, I.H.; Bateman, I.J.; Langford, H.D. A multilevel modelling approach to triple-bounded dichotomous choice contingent valuation. Environ. Resour. Econ. 1996, 7, 197-211.

32. Wilson, C.; Tisdell, C. Sea turtles as a non-consumptive tourism resource especially in Australia. Tour. Manag. 2001, 22, 279-288. [CrossRef]

33. Chun, J.H.; Lim, Y.W. Relationship between Tourism Interpretation Quality and Tourist Satisfaction in Ecotourism. J. Korea Acad. -Ind. Coop. Soc. 2016, 17, 520-527.

34. Geva, A.; Goldman, A. Satisfaction measurement in guided tours. Ann. Tour. Res. 1991, 18, 177-185. [CrossRef]

35. Lee, K.J.; Pan, Y. A Study on the Influence of Tour Guides' Self-leadership on Subjective Career Success-A Survey of Tour Guides for Chinese Travelers. J. Tour. Stud. 2015, 27, 33-59.

36. Mak, A.H.; Wong, K.K.; Chang, R.C. Factors affecting the service quality of the tour guiding profession in Macau. Int. J. Tour. Res. 2010, 12, 205-218. [CrossRef]

37. Moscardo, G. Mindful visitors: Heritage and tourism. Ann. Tour. Res. 1996, 23, 376-397. [CrossRef]

38. Rabotić, B. Tourist guides in contemporary tourism. In Proceedings of the International Conference on Tourism and Environment, Sarajevo, Bosnia and Herzegovina, 4-5 March 2010.

39. Black, R.; Weiler, B. Quality assurance and regulatory mechanisms in the tour guiding industry: A systematic review. J. Tour. Stud. 2005, 16, 24.

40. Lee, M.J. Different of the Educational Attributes Perception on the Tourism Resource Interpretation: The Case of Bulguksa. J. Tour. Leis. Res. 2000, 12, 185-199.

41. Mossberg, L.L. Tour leaders and their importance in charter tours. Tour. Manag. 1995, 16, 437-445. [CrossRef]

42. Heung, V.C.; Quf, H. Hong Kong as a travel destination: An analysis of Japanese tourists' satisfaction levels, and the likelihood of them recommending Hong Kong to others. J. Travel Tour. Mark. 2000, 9, 57-80. [CrossRef]

43. Huang, S.; Hsu, C.H.; Chan, A. Tour guide performance and tourist satisfaction: A study of the package tours in Shanghai. J. Hosp. Tour. Res. 2010, 34, 3-33. [CrossRef]

44. Hwang, S.N.; Lee, C.; Chen, H.J. The relationship among tourists' involvement, place attachment and interpretation satisfaction in Taiwan's national parks. Tour. Manag. 2005, 26, 143-156. [CrossRef] 
45. Wang, K.C.; Hsieh, A.T.; Chen, W.Y. Is the tour leader an effective endorser for group package tour brochures? Tour. Manag. 2002, 23, 489-498. [CrossRef]

46. Hanemann, W.M. Welfare evaluations in contingent valuation experiments with discrete responses. Am. J. Agric. Econ. 1984, 66, 332-341. [CrossRef]

47. Manski, C.F. The structure of random utility models. Theory Decis. 1977, 8, 229-254. [CrossRef]

48. Capps, O., Jr.; Kramer, R.A. Analysis of food stamp participation using qualitative choice models. Am. J. Agric. Econ. 1985, 67, 49-59. [CrossRef]

49. Bishop, R.C.; Heberlein Tna, A. Measuring values of extra market goods: Are indirect measures biased. Am. J. Agric. Econ. 1979, 61, 926-930. [CrossRef]

50. Luck, M. Contemporary issues in heritage and environmental interpretation. Ann. Tour. Res. 2000, 27, 1071-1074. [CrossRef]

51. Gonzalez, J.M.; Loomis, J.B.; Gonzalez-Caban, A. A joint estimation method to combine dichotomous choice CVM models with count data TCM Models corrected for truncation and endogenous stratification. J. Agric. Appl. Econ. 2008, 40, 681-695. [CrossRef]

52. Ramsey, F.; Goodwin, B. Rating Exotic Price Coverage in Crop Revenue Insurance. In Proceedings of the 2015 AAEA \& WAEA Joint Annual Meeting, San Francisco, CA, USA, 26-28 July 2015. Agricultural and Applied Economics Association \& Western Agricultural Economics Association(No. 205208).

(C) 2020 by the author. Licensee MDPI, Basel, Switzerland. This article is an open access article distributed under the terms and conditions of the Creative Commons Attribution (CC BY) license (http://creativecommons.org/licenses/by/4.0/). 